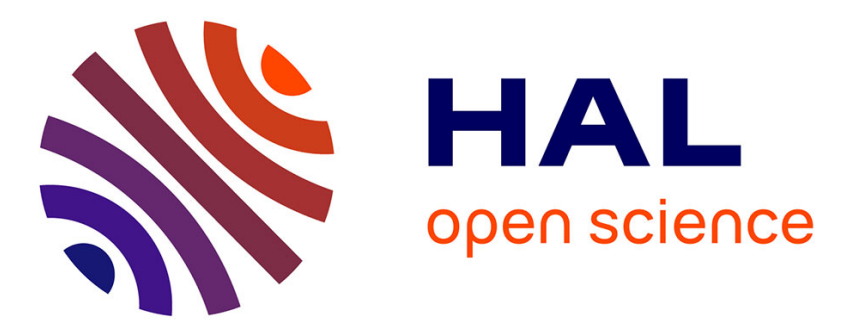

\title{
A Taxonomy for Personal Processes: Results from a Semi-structured Interview
}

\author{
Sercan Oruç, P. Erhan Eren, Altan Koçyiğit, Sencer Yeralan
}

\section{To cite this version:}

Sercan Oruç, P. Erhan Eren, Altan Koçyiğit, Sencer Yeralan. A Taxonomy for Personal Processes: Results from a Semi-structured Interview. 18th Conference on e-Business, e-Services and e-Society (I3E), Sep 2019, Trondheim, Norway. pp.771-782, 10.1007/978-3-030-29374-1_63 . hal-02510099

\section{HAL Id: hal-02510099 \\ https://hal.inria.fr/hal-02510099}

Submitted on 17 Mar 2020

HAL is a multi-disciplinary open access archive for the deposit and dissemination of scientific research documents, whether they are published or not. The documents may come from teaching and research institutions in France or abroad, or from public or private research centers.
L'archive ouverte pluridisciplinaire HAL, est destinée au dépôt et à la diffusion de documents scientifiques de niveau recherche, publiés ou non, émanant des établissements d'enseignement et de recherche français ou étrangers, des laboratoires publics ou privés. 


\title{
A Taxonomy for Personal Processes: Results from A Semi-Structured Interview
}

\author{
Sercan Oruç ${ }^{1[0000-0002-9995-9494],}$ P. Erhan Eren ${ }^{10000-0003-4354-3358]}$, Altan Koçyi ğit ${ }^{1[0000-0001-}$ \\ 5003-4127], and Sencer Yeralan ${ }^{2}$ [0000-0002-8689-5268] \\ ${ }^{1}$ Graduate School of Informatics, Department of Information Systems, Middle East Technical \\ University, Ankara, Turkey \\ sercanoruc@gmail.com, \{ereren, kocyigit\}@metu.edu.tr \\ ${ }^{2}$ Faculty of Engineering and Natural Sciences, International University of Sarajevo, Sarajevo, \\ Bosnia and Herzegovina \\ syeralaneius.edu.ba
}

\begin{abstract}
There are few studies conducted on personal processes within the business process management (BPM) domain. Personal processes are looser and more context- and person-dependent compared to the clearly defined business processes. This makes it more challenging to create solutions in this domain. In this study, a taxonomy is developed for personal processes. We used the data collected from semi-structured interviews that we have conducted with a diverse population. We built a taxonomy with 4 classes and 22 subclasses, further organized by 6 characteristics and 3 dimensions. The proposed taxonomy is intended to guide practitioners and researchers by identifying the range of processes, by understanding the relationship among process types, and by organizing the knowledge within the Personal Process Management (PPM) domain. As such, our work would lead to creating new methods, tools, and approaches for increased effectiveness of PPM solutions.
\end{abstract}

Keywords: Business Process Management, Personal Process Management, Taxonomy, Semi-structured Interview

\section{$1 \quad$ Introduction}

Personal Process Management (PPM), as an extension to Business Process Management (BPM), focuses on the processes within people's personal lives. Planning a marriage event, choosing and registering for a college, making soup, or applying for a visa are some examples of personal processes. In many cases, personal processes highly depend on the context and the individuals involved.

Several taxonomies are suggested within the Business Process Management (BPM) domain, i.e. for BPM techniques [1], requirement changes attributes [2], unstructured workflows [3], execution exceptions [4], process flexibility ([5, 6]) and time rules [7]. Yet, no taxonomy has ever been developed with a focus on personal processes.

Taxonomies construct the knowledge core of domains which help the researchers to understand and analyze them and lead to an improvement in corresponding do- 
mains [8]. This statement also defines the main motivation behind this study: to create the knowledge core in the PPM domain and support the practitioners with an overview of personal processes so that different applications, methods or approaches can be developed for different classes. As study [8] highlights, it is necessary to create classifications for more advanced theories. Taxonomies not only reduce confusion but also aid understanding [9]. Nickerson et al. [10] list various studies showing the role of taxonomies in the information systems (IS) research literature and state that "classification is a fundamental mechanism for organizing knowledge".

The main objective of this paper is to propose a personal process taxonomy by using the method suggested by Nickerson et al. [10]. Accordingly, we conducted semistructured interviews with 20 people of different ages and occupation groups. From those interviews, more than 60 process examples emerged. Using the responses, we applied an inductive approach of taxonomy development following [10]. We define the personal process taxonomy step by step by listing classes, subclasses, and their properties, and by illustrating each of them by giving examples.

This paper is organized as follows. In section 2, we outline taxonomy studies conducted within the BPM domain. In section 3, we justify and describe the method that we have used. In section 4 , we describe the resultant personal process taxonomy in detail. Finally, in section 5, we conclude the paper with discussion of the contributions of this paper, and future work.

\section{Taxonomy Studies in BPM Domain}

In the BPM domain, there are several studies proposing taxonomies from various perspectives. [11] shows an ontological model and a taxonomy of BPM systems. It also shows the hierarchy of interface, execution engine, metrics and their subclasses pertinent to software industry BPM systems. Shaw et al. [12] propose a BPM system architecture showing core technologies as building blocks. They list the full set of levels and core technologies and how they merge into a BPM system along with the transmission and processing of modeling characteristics. [9] highlights a taxonomy that would be used in expressing the purpose of any evaluated BPM technology.

Study [1] gives a taxonomy of business process modeling and IS modeling techniques. It states that the taxonomy can be used in evaluating and selecting suitable modeling techniques by the decision makers, depending on the needs of the projects. On the other hand, in [13], project types in BPM are classified and three major and two minor classes by using multivariate data analysis techniques are suggested.

In study [14], a list of BPM and flow automation definitions are made and a standard set of terms and concepts to support clear communication in industry are given. Five BPM categories are listed to make the clarification: Administrative and Task Support (Visual), Team Process Support Tools (Collaborative), Application Specific (Preconfigured), Integration-Focused, and Application Independent.

In study [7], Arevalo et al. focus on the temporal dimension of business processes and define a time rule taxonomy which leads to "business temporal rules with current BPMN standard" in a declarative way. 
In study [4], Zhao et al. try to find solution to the deficiency in support for exception handling for current business process programming languages for semantic web services by providing an exception taxonomy.

In [2], a taxonomy of change with four main classes are suggested: "time of change", "origin of change", "type of change", and "structural effect of change" that can be used in detecting changes before they are reported. A taxonomy for BPM flexibility with a focus of change is also suggested in study [6]: abstraction level of change, subject of change, and properties of change.

[5] gives a taxonomy of process flexibility by listing four types: flexibility by design, deviation, underspecification, and change. This distinction is made based on the conducted literature study. These four categories are evaluated, and it is seen that these types can be found in the literature and in practice.

In summary, within the BPM domain, there is a wide spectrum of taxonomy studies including taxonomies of technologies, modeling techniques, project types, definitions, temporal dimension of processes, exceptions, change, and flexibility. Yet, these examples do not suggest a taxonomy directly from the processes themselves.

There are two studies which have similarity with ours by directly focusing on the processes themselves. The first one is presented by [3] which gives a taxonomy of unstructured workflows with the aim of analyzing those workflows and determining if they can be changed into equivalent structured forms. Yet, this study creates the taxonomy using the relationship of the control elements of the workflows, regardless of the context or the domain of the process.

In the second study [15], a systematic literature review is conducted and organizational information-processing theory is employed to identify the differences among processes. The goal is to minimize the wasted efforts by understanding different management requirements for different processes. By using the data obtained from other studies within the literature, this study considers context-specific BPM practices. Yet, its scope covers business processes within organizations. None of these studies outlines a taxonomy of processes within everyday life considering contextual factors.

\section{Method}

In this study, first we conducted semi-structured interviews with 20 respondents to bring up a set of personal processes. Then, we used the responses from the interviews in developing a personal process taxonomy. In taxonomy development, we followed the seven-step method proposed in study [10] which is also used by many IS research, i.e. [15-18]. Study [10] presents a better alternative to ad hoc way of developing taxonomy in the IS domain by showing that the proposed method has requisite qualities developed based on well-established taxonomy development literature.

\subsection{Data Collection: Semi-Structured Interview}

To understand things that cannot be observed like experiences, attitudes, thoughts, intentions, comments, perceptions, and reactions; qualitative researchers use inter- 
viewing as an effective method [19]. We used semi-structured interviews to gather information from a diverse population. As it is stated in [20], "the semi-structured interview provides a repertoire of possibilities". While the interview is structured enough to point to a specific topic, it also leaves space to the participants to offer new ideas. The questions are mostly open-ended, which allows the discovery and gathering of unforeseen or unpredicted information.

The Sample of the Study. In this study, we used diversity (maximum variation) sampling, which is a type of purposive (judgmental) sampling. We interviewed 20 people from 18 distinct occupations. The minimum conditions for selecting the participants were that the participant should be using a mobile device and that should be actively managing the daily life processes of themselves. We tried to reflect the diversity of the population within the sample by choosing from different genders, age groups, occupations, and education degrees. The age distribution of participants can be seen in Fig. 1. The youngest participant is 22 years old whereas the oldest one is 60 . The education levels of the participants can be seen in Fig. 2.

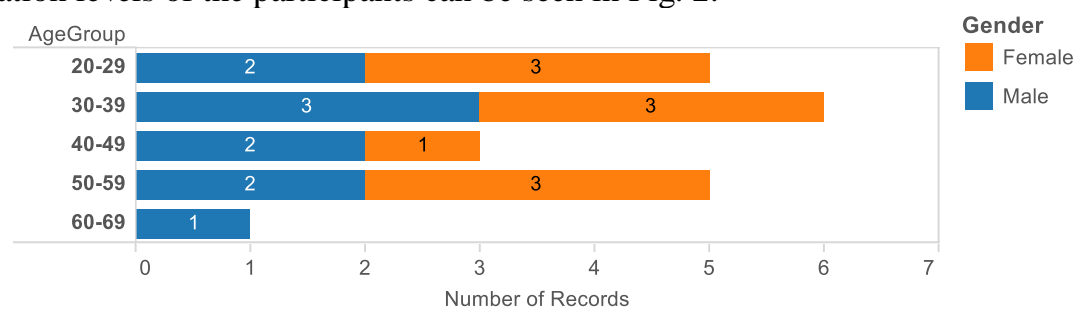

Fig. 1. Age Distribution

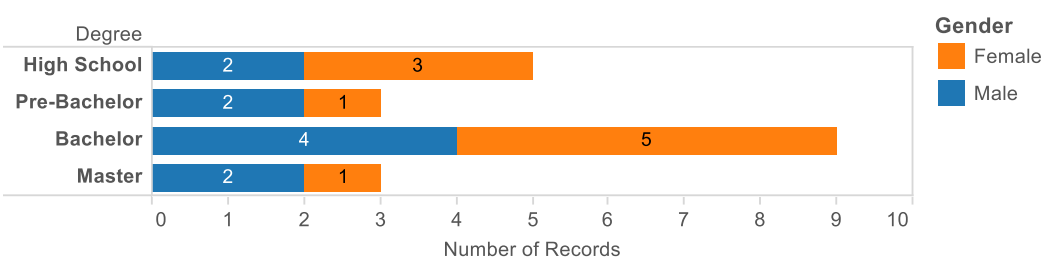

Fig. 2. Educational Degree Distribution

\subsection{Seven Steps of Taxonomy Development}

To develop a taxonomy by the personal processes gathered from the semi-structured interview, we followed the seven-step method proposed by Nickerson, Varshney and Muntermann (2013). Fig. 3 shows the steps of the taxonomy development method. 


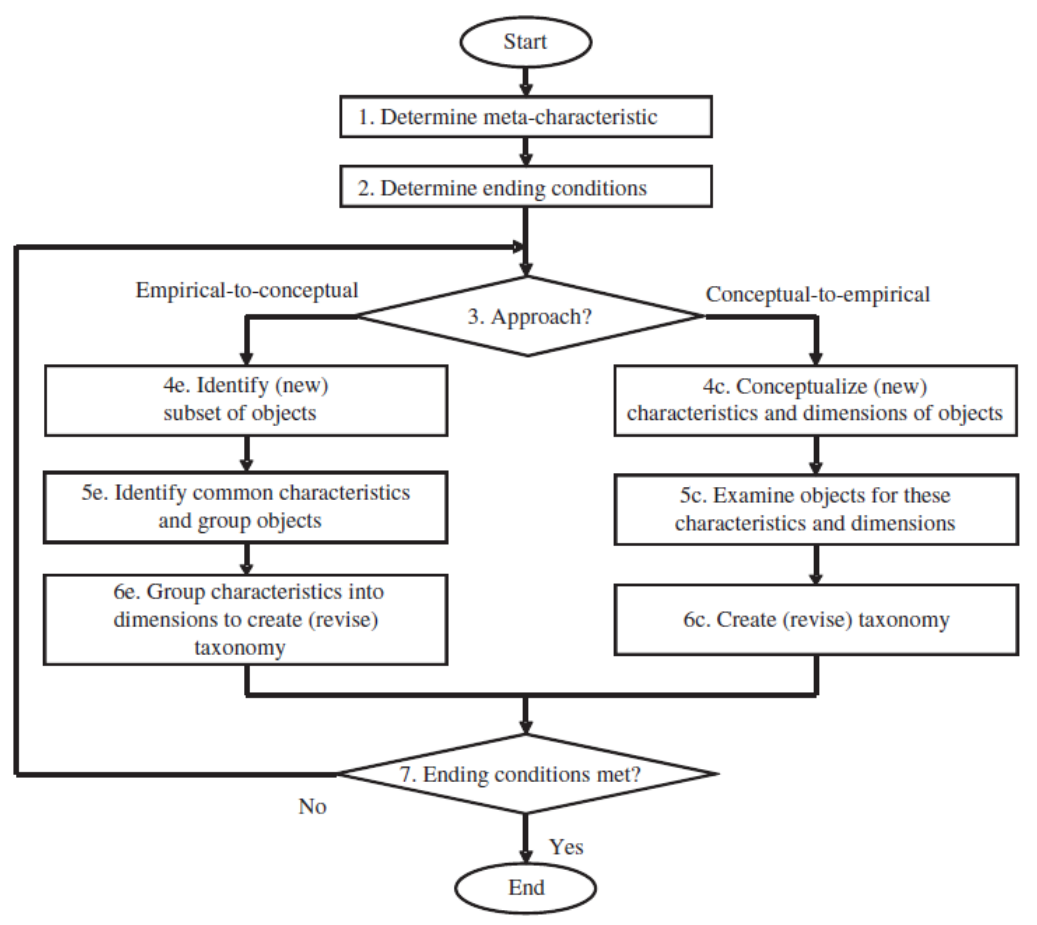

Fig. 3. The taxonomy development method [10].

Step 1 - Determine meta-characteristics. Meta-characteristic is defined in [10] as "the most comprehensive characteristic that will serve as the basis for the choice of characteristics in the taxonomy". Our goal is to structure personal processes related knowledge. The target users are both researchers and practitioners interested in personal processes who may create new applications, methods or approaches for managing personal processes. The scope of the taxonomy is limited to processes of people using a mobile device and actively managing the daily life processes of themselves. In these terms, processes of a person such as a child using a mobile phone yet having a life highly dependent on parents, or an elder living independently in a community yet not using a mobile device does not fall within the scope of this study. Considering all these aspects, we define the meta-characteristics of our taxonomy as 'connection between the management approach of the process owner and the personal process'.

Step 2 - Determine ending conditions. We used eight objective and five subjective ending conditions proposed in study [10]. These conditions determine when to end the process of developing the taxonomy.

Step 3 - Approach. We used inductive (empirical-to-conceptual) approach for all three iterations. 
Step 4,5 and 6 - Identify a Subset of Objects, Identify Common Characteristics and Group Objects, Group Characteristics into Dimensions to Create Taxonomy. In each iteration, we evaluated a new subset of personal processes gathered from the semi-structured interview. At the end of the three iterations, we finished evaluating all the personal processes gathered from the interviews. The outcome is the following common characteristics:

- Essential: Some processes are essential to have an independent daily life.

- Optional: Some processes are optional in terms of having an independent daily life.

- Routine: Some processes routinely take part in personal lives.

- Ad Hoc: Some processes occur in an ad hoc manner.

- Obliged: Some processes are completed to fulfill some obligations. These processes emerge from something the person owns or is responsible for.

- Not Obliged: Some processes emerge from something other than the things that the person owns or is responsible for.

We grouped these characteristics into three dimensions:

- D1: Necessity (Essential, Optional)

- D2: Occurrence (Routine, Ad Hoc)

- D3: Obligation (Obliged, Not Obliged)

Step 7 - Ending Conditions Met? At the end of the third iteration, ending conditions are met and we concluded the taxonomy development.

\section{Taxonomy of Personal Processes}

Using the characteristics in the previous section, we defined a personal process taxonomy as in Table 1. We grouped the process examples that we have collected from the semi-structured interviews, in four groups: Diversions, Emergencies, Instrumental Activities of Daily Living (IADL), and Responsibilities. Those four classes have 22 subclasses in total. During the development process of the taxonomy, we kept in mind to bring the qualitative attributes listed in [10] to the taxonomy: concise, robust, comprehensive, extendible, and explanatory.

\subsection{Instrumental Activities of Daily Living}

Activities of Daily Living (ADL), Basic Activities of Daily Living (BADL) and IADL terms are well known terms used in healthcare. BADL are needed for fundamental functioning of a person whereas IADL are needed additionally to have an independent life in a community. We considered using IADL not BADL, as we interpreted that managing BADL with some IS would not be effective. BADL consist of the following 'toilet hygiene', 'self-feeding', 'dressing', 'grooming', 'physical ambulation', and 'bathing' [21]. 
Table 1. Personal Process Taxonomy

\begin{tabular}{|c|c|c|c|c|c|c|c|}
\hline & \multicolumn{2}{|c|}{ D1: Necessity } & \multicolumn{2}{|c|}{ D2: Occurrence } & \multicolumn{2}{|c|}{ D3: Obligation } \\
\hline & & $\begin{array}{c}\text { Essen- } \\
\text { tial }\end{array}$ & $\begin{array}{l}\text { Op- } \\
\text { tional }\end{array}$ & $\begin{array}{l}\text { Rou- } \\
\text { tine }\end{array}$ & $\begin{array}{c}\text { Ad } \\
\text { Hoc }\end{array}$ & $\begin{array}{c}\text { Obli } \\
\text { ged }\end{array}$ & $\begin{array}{c}\text { Not } \\
\text { Obliged }\end{array}$ \\
\hline \multirow{4}{*}{ 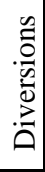 } & Exercising & & $\mathrm{X}$ & $X$ & $\mathrm{X}$ & & $\mathrm{X}$ \\
\hline & Hobbies & & $\mathrm{X}$ & $\mathrm{X}$ & $\mathrm{X}$ & & $\mathrm{X}$ \\
\hline & Social Activities & & $\mathrm{X}$ & $\mathrm{X}$ & $\mathrm{X}$ & & $\mathrm{X}$ \\
\hline & Travelling & & $\mathrm{X}$ & $\mathrm{X}$ & $\mathrm{X}$ & & $\mathrm{X}$ \\
\hline \multirow{4}{*}{ 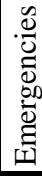 } & Accidents & $\mathrm{X}$ & & & $\mathrm{X}$ & & $\mathrm{X}$ \\
\hline & Injuries and Sickness & $\mathrm{X}$ & & & $\mathrm{X}$ & & $\mathrm{X}$ \\
\hline & Missing Flight/Train/Bus Case & $\mathrm{X}$ & & & $\mathrm{X}$ & & $\mathrm{X}$ \\
\hline & Lost Wallet Case & $\mathrm{X}$ & & & $\mathrm{X}$ & & $\mathrm{X}$ \\
\hline \multirow{7}{*}{ 完 } & Handling Finances & $\mathrm{X}$ & & $X$ & & & $\mathrm{X}$ \\
\hline & Housework & $X$ & & $\mathrm{X}$ & & & $X$ \\
\hline & Mode of Transportation & $\mathrm{X}$ & & $X$ & & & $\mathrm{X}$ \\
\hline & Preparing Meals & $\mathrm{X}$ & & $X$ & & & $\mathrm{X}$ \\
\hline & Shopping & $\mathrm{X}$ & & $\mathrm{X}$ & & & $\mathrm{X}$ \\
\hline & Taking Medication as Prescribed & $X$ & & $X$ & & & $X$ \\
\hline & Use forms of communication & $\mathrm{X}$ & & $\underline{X}$ & & & $\mathrm{X}$ \\
\hline \multirow{7}{*}{ 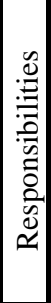 } & Business Processes & & $X$ & $X$ & $\mathrm{X}$ & $X$ & \\
\hline & Care of Pets & & $\mathrm{X}$ & $\mathrm{X}$ & $\mathrm{X}$ & $\mathrm{X}$ & \\
\hline & Child Rearing & & $\mathrm{X}$ & $\mathrm{X}$ & $\mathrm{X}$ & $\mathrm{X}$ & \\
\hline & Citizenship Responsibilities & & $\mathrm{X}$ & $X$ & $\mathrm{X}$ & $\mathrm{X}$ & \\
\hline & Garden Care & & $\mathrm{X}$ & $\mathrm{X}$ & $\mathrm{X}$ & $\mathrm{X}$ & \\
\hline & Real Estate Care & & $\mathrm{X}$ & $\mathrm{X}$ & $\mathrm{X}$ & $X$ & \\
\hline & Vehicle Care & & $\mathrm{X}$ & $\mathrm{X}$ & $\mathrm{X}$ & $\mathrm{X}$ & \\
\hline
\end{tabular}

A modification of IADL listed in [21] has 7 subclasses:

- Handling finances (stated as "ability to handle finances" in [21]).

- Housework, (stated as "housekeeping" and "laundry" in [21])

- Mode of transportation,

- Preparing meals (stated as "food preparation" in [21]),

- Shopping,

- Taking medication as prescribed (stated as "responsibility for own medications" in [21]),

- and Use a form of communication (stated as "ability to phone" in [21])

Handling Finances: Although money management is mostly about decision making, processes can also be very vital as in the example of invoice payment timings.

Housework: An example process emerges after a dinner consist of activities: clearing the table, loading the dishwasher, starting the dishwasher, wiping the table, sweeping the floor, emptying the dishwasher, putting the dishes into the cupboards.

Mode of Transportation: Using different means of transportation may lead to different processes. For instance, going from one point to another in a city by mass 
transportation may have activities like getting on a bus number $X$, then going 3 stations by tram, finally walking 400 meters.

Preparing Meals: Any dish recipe, which list actions to be completed in a given order, is a good example for a "Preparing Meals" type of process.

Shopping: The person may have a long shopping list. There could be many shop and product alternatives. Also, the timing, following the discounts, or closeness to the shops could be some possible concerns of the person. If the person wants to optimize the time and money he spends, or the quality he buys, then the process of shopping becomes computationally complex.

Taking Medication as Prescribed: Taking medication is a common part of any medical care. Usually the timing and dosage of taking medication are significantly important. So, tracking the process becomes more important.

Use A Form of Communication: This subclass is composed of many atomic activities like making a phone call or sending an e-mail. Combining these activities with other surrounding activities, we get some simple processes. For instance, we can think of a person starting her computer and sending an e-mail (signing in, writing the email, entering to-cc-bcc lists, sending the e-mail).

\subsection{Responsibilities}

This class consists of processes that emerge from the things that the person owns or is responsible for. For instance, if the person owns a dog, then she should handle the processes regarding dog care like tracking the vaccination guidelines or meeting the daily needs of walking or feeding. Although there are fewer than 10 subclasses listed under the class "responsibilities", the number can easily increase depending on the variety of belongings the person has.

Business Processes: Business processes serve for organizational goals. This collection of activities takes place in a person's life in case that person has a business. From the perspective of that single person, business processes that she is involved in are processes as a set of responsibilities in her personal life. Depending on the organizational culture and policies, sometimes these processes intertwine with other, more personal processes. In the first case, there could be a more effective way of managing this collection of processes by dealing with them all together.

Care of Pets: Some examples would be taking the dog to walks periodically or following vaccination schedules of the pet.

Child Rearing: Some activities that would exemplify such processes would be feeding, playing, or taking the child to a doctor.

Citizenship Responsibilities: Having a citizenship from a country comes with many processes to be completed. Some examples could be voting or compulsory military service in countries or serving jury duty.

Garden Care: Watering the grass, disinfecting the tools, controlling the weeds, and mulching are some activities that may take place in garden care processes.

Real Estate Care: For instance, a person having a house should complete house maintenance tasks in the lifespan of that house, like inspecting the fire extinguisher, 
getting the air conditioner ready for the summer, getting the chimney cleaned, or paying the taxes of the house.

Vehicle Care: Some examples would be changing the tires, getting the car cleaned, or keeping up with insurance payments.

\subsection{Diversions}

"Diversions" are the processes that divert from basic or instrumental daily living processes and responsibilities. The causes or motivations behind those processes are intangible things like happiness, health, curiosity, etc. "IADL" processes should take place in a person's life in order for him to have an independent life in a community.

Exercising: This subclass consists of mostly structured processes. These processes could be created by domain experts and followed by the person.

Hobbies: Following a guitar lesson, doing ear training, improving the technique, practicing scales, chords, or arpeggios could be given as example activities that would form a personal process of learning guitar.

Social Activities: This subclass consists of social events like organizing a home party or some gathering activity with some friends. Processes related with social activities are mostly people centric as the main purpose of social activities are consorting with or joining with other people.

Traveling: Arranging for flight and hotel, listing the attraction points in a city, and the order of visiting these attraction points can be given as examples of activities and relations that would create traveling type of processes.

\subsection{Emergencies}

The fourth class consists of processes that are completed in unplanned occasions like "what should a person do when he has lost his wallet?" or "what should a person do when she misses her flight?". Following four examples are collected from the semistructured interviews that we have conducted. The number of subclasses can be increased by collecting new example cases.

Accidents: The activities that should be performed when an accident occurs would create processes to be considered under the accidents subclass.

Injuries: The activities that should be performed when an injury occurs would create processes to be considered under the injuries subclass.

Lost Wallet Case: If a wallet is lost, what should the person do? The answer would create a process. As an example answer: the person should think of the last time he saw the wallet, and ask the people who might have seen it and check the places he passed since then. If he couldn't get a positive response, he should call the banks depending on the credit or bank cards in his wallet, so that he can cancel those cards. He should inform the police that he has lost his ID cards. Depending on the items he has lost with his wallet, new activities can be added to the process. The order of the activities would mostly be affected by the importance and urgency of the activities.

Missing Flight/Train/Bus Case: The activities that should be performed when a person misses a flight, train, bus, etc. 


\section{$5 \quad$ Discussions and Conclusions}

In this paper, we propose a taxonomy for personal processes by using the method presented by [10] as it is "based on well-established literature in taxonomy development". As the input data for the taxonomy development, we used the empirical results of semi-structured interviews that we have conducted with a diverse population. As a result, in this taxonomy, there are four main classes which are composed of 22 subclasses in total. The taxonomy is open for extension in terms of new classes and subclasses. The following questions would help in defining the properties or attributes of corresponding subclasses and the related processes.

How frequently is the process executed? The number of times in a period that a person completes a process would also be considered as an important dimension. Some personal processes are completed just once or twice in a lifetime (low frequency) as in the example of marriage. Some personal processes are completed much more frequently (high frequency) like preparing breakfast. There are also some other processes that are in between high and low frequency personal processes (medium frequency) as in the example of course registration in a university. For instance, in some universities, a student completes course registration twice in a year for 4 years. There are two important points here in this question:

- Although it is not necessarily needed, it is difficult to set specific boundaries (number over time) to define which processes are in classes high, medium, or low frequencies. The borders may even change from person to person.

- Having fuzzy boundaries between frequency classes does not affect the importance of having those classes.

How important/critical/serious is the process? Some processes are more critical than the others. The actions of that process must be followed completely without any errors. The process of following medical treatment routines is more critical than the process of traveling. Some actions in seeing a city may be skipped without any critical consequences. Yet, it would not be the same for skipping an action in the process of some medical treatment.

Does the process have a legislative, a regulation, or some other strict process definition? If the process is executed depending on a legislative process, then it is assumed that the steps cannot be changed. The case whether the process has a legislative or not would affect the flexibility of it. This type of processes also takes significant amount of time in personal lives. Driver's license registration or child adoption processes can be given as examples.

Is the process data driven or judgment driven? Some processes can be managed more effectively by solely using the available data and some predefined objectives like minimizing time, money, or energy consumption. On the other hand, other processes are affected more by the judgments of the person. The process of profession selection is more like a judgment driven process than a data driven process whereas visa application process is a data driven process. 
The sample size and extent of the semi-structured interview is rather limited, as we consider our work as an initial investigation of the validity of the approach, and to assess its expected success. As the development of any class of mobile and computer applications is an evolutionary process, the initial first steps are usually taken in small increments, while the validity and the appropriateness of the approach are frequently and carefully monitored and evaluated. Corrections at the beginning are clearly easier, more efficient, and less intrusive than latter ones. Given the encouragement of the initial limited survey, and now equipped with the experiences from this initial probe, we are now confident to extend and expand our investigation. The purpose of the dissemination of our findings is to avail others from joining our effort and giving them head start so that they do not need to start from scratch.

The role of this taxonomy is to guide practitioners and researchers by structuring personal process classes, making the relationship among process types clear, and arranging the knowledge within the PPM domain. This understanding would eventually help practitioners and researchers in suggesting methodologies or techniques to be used in effective management of personal processes.

As in any academic study, we take a promising idea and push it to its logical and practical limits to evaluate its usefulness. The current study is an attempt to best address the robust development of the emerging field, and subsequent applications of PPM. As in any academic study, one cannot guarantee the eventual unqualified success of the approach taken. However, reporting on the results of the diligent and honest scientific efforts is an enriching contribution to the body of academic literature. Our initial study and experience indicate that our work has so far provided encouragement for its usefulness and eventual benefits.

The paper is a report on the work accomplished so far. The development of a PPM system is a complex issue which will most likely take time to evolve and mature before it settles into a universally accepted technology. Our approach is to embark on this process following the most scientifically rigorous methodologies available. Accordingly, we dwell on a taxonomy, which we hope will not only start the research and development process on a scientific footing, but also facilitate the emergence of heterodoxical approaches not immediately available through customary software development efforts.

\section{References}

1. Giaglis, G.M.: A Taxonomy of Business Process Modeling and Information Systems Modeling Techniques. Int. J. Flex. Manuf. Syst. 13, 209-228 (2001).

2. Mathisen, E., Ellingsen, K., Fallmyr, T.: Using business process modelling to reduce the effects of requirements changes in software projects. In: 2009 2nd International Conference on Adaptive Science \& Technology (ICAST). pp. 14-19. IEEE (2009).

3. Liu, R., Kumar, A.: An Analysis and Taxonomy of Unstructured Workflows. Presented at the (2005).

4. Zhao, K., Zhang, L., Ying, S.: Ontology-Based Exception Handling for Semantic Business Process Execution. J. Softw. 7, (2012). 
5. Schonenberg, M.H., Mans, R.S., Russell, N.C., Mulyar, N.A., W.M.P. Aalst, van der: Towards a taxonomy of process flexibility (extended version), (2007).

6. Regev, G., Soffer, P., Schmidt, R.: Taxonomy of Flexibility in Business Processes. BPMDS. (2006).

7. Arevalo, C., Escalona, M.J., Ramos, I., Domínguez-Muñoz, M.: A metamodel to integrate business processes time perspective in BPMN 2.0. Inf. Softw. Technol. 77, 17-33 (2016).

8. Glass, R.L., Vessey, I.: Contemporary application-domain taxonomies. IEEE Softw. 12, 63-76 (1995).

9. SAP, Accenture: BPM Technology Taxonomy. (2009).

10. Nickerson, R.C., Varshney, U., Muntermann, J.: A method for taxonomy development and its application in information systems. Eur. J. Inf. Syst. 22, 336-359 (2013).

11. Manoilov, G., Deliiska, B., Todorov, M.D.: Ontological Model of Business Process Management Systems. In: AIP Conference Proceedings. pp. 491-499. AIP (2008).

12. Shaw, D.R., Holland, C.P., Kawalek, P., Snowdon, B., Warboys, B.: Elements of a business process management system: theory and practice. Bus. Process Manag. J. 13, 91-107 (2007).

13. Bucher, T., Winter, R.: Project types of business process management. Bus. Process Manag. J. 15, 548-568 (2009).

14. Sinur, J., Bell, T.: Gartner A BPM Taxonomy: Creating Clarity in a Confusing Market. (2003).

15. Zelt, S., Schmiedel, T., vom Brocke, J.: Understanding the nature of processes: an information-processing perspective. Bus. Process Manag. J. 24, 67-88 (2018).

16. Seyffarth, T., Kühnel, S., Sackmann, S.: A Taxonomy of Compliance Processes for Business Process Compliance. Presented at the (2017).

17. Reman, G., Hanelt, A., Tesch, J.F., Kolbe, L.M.: The Business Model Pattern Database - A Tool For Systematic Business Model Innovation. Int. J. Innov. Manag. 21, 1750004 (2017).

18. Lehnert, M., Linhart, A., Roeglinger, M.: Exploring the intersection of business process improvement and BPM capability development. Bus. Process Manag. J. 23, 275-292 (2017).

19. Yıldırım, A., Şimşek, H.: Research Methods in Social Sciences. Seçkin Yayıncılık (2006).

20. Galletta, A.: Mastering the semi-structured interview and beyond: from research design to analysis and publication. (2013).

21. Lawton, M.P., Brody, E.M.: Assessment of Older People: Self-Maintaining and Instrumental Activities of Daily Living. Gerontologist. 9, 179-186 (1969). 